\title{
Crossrail project: environmental management during delivery of London's Elizabeth line
}

1 Rob Paris MSC, MCIWEM, MEIS

Head of Sustainability and Consents, Crossrail Limited, London, UK

2 Cathy Myatt MA, MSC

Environment Manager, Crossrail Limited, London, UK
3 Mike de Silva BSC, PhD, FCIWEM, MIEEM, CSCi, CWEM Sustainability Manager, Crossrail Limited, London, UK
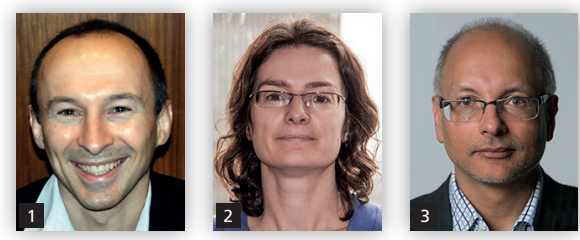

Crossrail, the $\mathbf{f} 14.8$ billion project to deliver the Elizabeth line east-west railway across London, is the largest construction project in Europe. This paper focuses on the environmental management practices that were employed during delivery of the central tunnelled section of the line. The aim was to promote and achieve a high level of environmental performance during construction, which in turn would set a new benchmark for environmental performance when delivering major transport infrastructure.

\section{Introduction}

The $£ 14.8$ billion Crossrail project to deliver the Elizabeth line east-west railway across London, UK, is currently the largest infrastructure project in Europe and is one of the most ambitious projects ever undertaken in the UK. It involves delivering $118 \mathrm{~km}$ of new railway, including $42 \mathrm{~km}$ of new tunnels and ten new stations. The route connects Reading and Heathrow in the west to Canary Wharf, Abbey Wood and Shenfield in the east, spans 20 local authority areas and, when fully operational, will add $10 \%$ to central London's rail capacity.

The central section shown in Figure 1 in red is mainly in tunnel. The surface sections are located in existing railway corridors, mainly the Great Western and Great Eastern main lines. The central section is being delivered by Crossrail Limited together with its partners and contractors, and the surface works are being delivered by Network Rail. The project is jointly sponsored by the UK Department for Transport and Transport for London.

\section{Environmental Minimum Requirements}

Crossrail is a 'hybrid bill' scheme with the deemed planning permission and the powers to construct, maintain and operate the Elizabeth line coming from the Crossrail Act 2008. A hybrid public-private bill together with other key documentation including an environmental statement was submitted to the UK parliament to go through the necessary select committee process to obtain approval for the project (Bennett, 2017).

During the parliamentary process, negotiations took place with all affected local authorities and the statutory agencies such as the Environment Agency and Natural England. This resulted in the production of a suite of documents known as the Environmental Minimum Requirements (EMR; Crossrail, 2017). There are several documents in the EMR, but the key ones for the purposes of this paper are the Construction Code and the Environmental Memorandum.

The Environmental Memorandum chiefly governs how the project must be managed and designed to take account of and

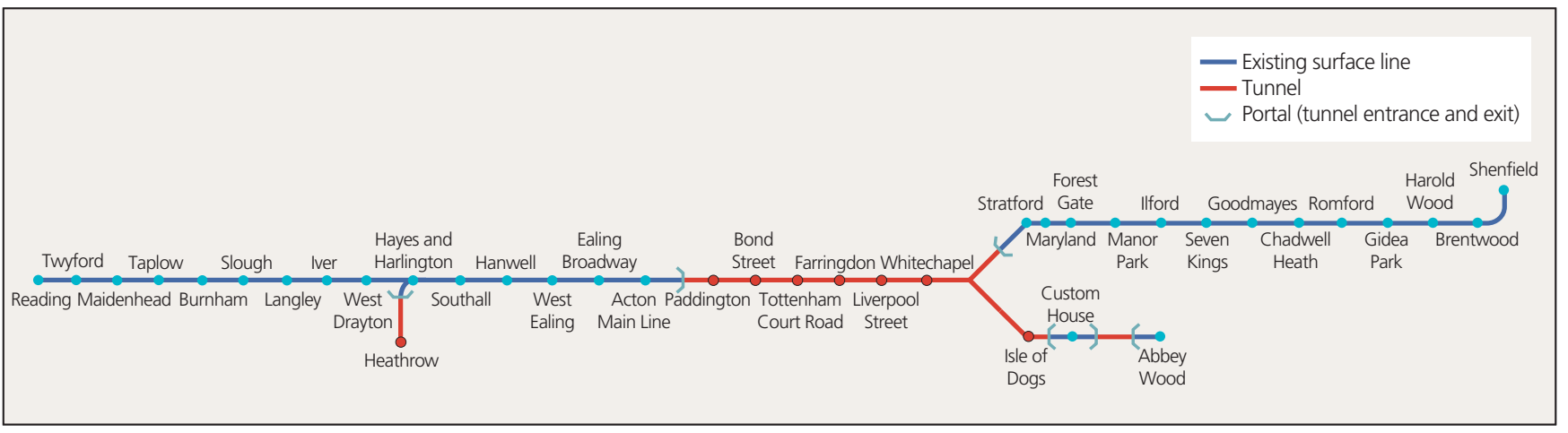

Figure 1. The Elizabeth line route 
reduce its environmental impacts. The Construction Code incorporated all of the environmental mitigation assumed in the environmental statement, and also drew on the environmental management plans of the local authorities and the best-practice management plans from the major infrastructure projects being delivered at around that time, such as High Speed 1, Thameslink and Heathrow Terminal 5. It therefore represented the current industry best practice at the time.

The secretary of state gave a commitment that any organisation that was subsequently authorised under the Crossrail Act 2008 to deliver any part of the project (the nominated undertaker) would be contractually bound to comply with the EMR. Crossrail Limited was appointed as the nominated undertaker and was bound under the project development agreement.

The outcome was that best practice became the project's minimum environmental requirement. It also ensured the cascading of the mitigation from the environmental statement into the delivery of the project.

\section{Adverse environmental impacts and challenges}

The environmental statement identified a number of significant adverse environmental impacts across the route, but the majority were associated with the construction phase and consisted predominantly of noise and visual impacts.

It also identified a number of significant traffic and transport impacts associated with road diversions and closures, plus a routewide ecology impact due to the clearance of lineside vegetation on the surface sections. These, plus other less common localised impacts, represented a key challenge to delivering the project in the built-up residential and commercial areas of London (Figure 2).

The environmental statement also identified a number of key environmental challenges. These were not significant impacts in themselves but, by their nature and scale, nevertheless represented key areas where high levels of environmental performance would be essential. The key issues were as follows.

- Fate of excavated material - the environmental statement predicted that over 6 million $\mathrm{m}^{3}$ of surplus excavated material

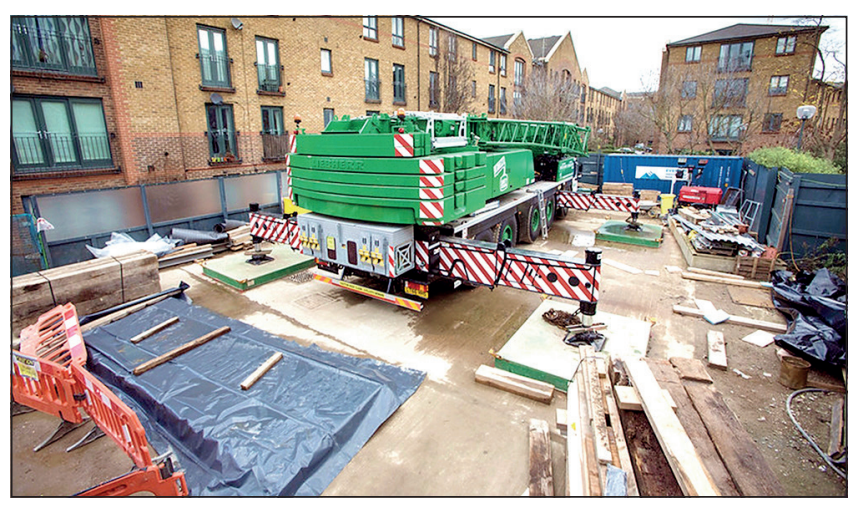

Figure 2. Construction on small sites immediately adjacent to residential properties would be generated from the excavation of tunnels, stations and shafts. For the purposes of the environmental statement it was necessary to demonstrate that a reasonable solution could be identified, and a strategy was presented whereby the majority of the excavated material was taken to landfill sites where it would be used beneficially for capping and cell construction. However, it was recognised that there ought to be better beneficial reuse options to adopt, but that it was simply too early in the project's life to identify them. Therefore the EMR contained a requirement for the waste hierarchy to be employed, and that suitable projects or other opportunities for reuse of the excavated material would be identified as the detailed construction planning of the project progressed. Another key objective set by the EMR was to remove, where reasonably practicable, excavated material by rail and water transport.

- Archaeological programme of works - given the historical location of the project on existing lines as well as through the heart of London, the archaeological programme of works was probably going to be one of the largest ever undertaken in the UK. As such, it needed to be carried out in a way that was sensitive to what was found but in a way that would avoid impeding the project programme.

- Carbon dioxide footprint - this was included in the environmental statement and went through a number of refinements as the detailed design progressed and as better predictive information, such as emission factors and embodied carbon dioxide, became available. By 2010 it showed that, depending on certain assumptions such as grid mix, operation of the Elizabeth line should pay back its capital carbon dioxide in 9-13 years. While this represented a positive position, it was incumbent on the project to reduce capital carbon dioxide as far as reasonably practicable and produce designs that promoted energy-efficient operation to reduce the payback period.

- Use of natural resources - building the Elizabeth line would require significant use of natural resources and the environmental statement, for example, estimated 1 million $\mathrm{m}^{3}$ of concrete and $140000 \mathrm{t}$ of steel would be required for construction.

\section{Procurement strategy}

In addition to the environmental impacts and challenges of such a large project, further complexity was added by the procurement strategy, with numerous designers, contractors and partner organisations involved in delivering the project (Lloyd-Davies and Rowark, 2017).

Managing the interfaces and ensuring consistency of approach and reporting, as well as dealing with cumulative impacts of more than one contract in the same location, became major challenges in their own right. The central section was delivered by 23 framework design consultants, 33 enabling works contractors and 40 main works contractors. There were also several route-wide contracts such as the archaeology and noise insulation contracts that worked across the whole of the central section. In total, there were over 170 contracts delivering the central section works.

As mentioned in Section 1, the surface sections of the route were delivered by Network Rail, working as a partner organisation and procuring its works under a number of different contracts. 
Other partners were involved at specific locations, including utility companies (delivering utility works on their infrastructure), London Underground, Canary Wharf Group (Canary Wharf station) and Berkeley Homes (Woolwich station).

Many of the route-wide contracts played an important role in the delivery of certain aspects of environmental management. For example, the procurement programme for the principal contractors did not provide sufficient lead time to identify and provide noise insulation to properties that were predicted to exceed certain trigger levels agreed during the parliamentary process. As a result, the design consultants were required to carry out modelling to identify these properties and two route-wide specialist glazing contracts were procured which then installed the insulation.

Similarly, in response to the challenges posed by the archaeological programme, the client procured specialist archaeological contracts and managed them centrally so that they could be delivered at any particular site at the required point in the programme. As a result of this approach, since construction began in 2009 over 100 archaeologists have found tens of thousands of items from 40 sites, spanning 55 million years of London's history and pre-history - all without compromising the project's construction programme (Carver, 2014). More on the archaeological work for the project can be found in the archaeology topic area of the Learning Legacy website (Crossrail Learning Legacy, 2016).

At some locations, two or more contractors and/or partners were carrying out works at the same time and issues of coordination and cumulative impacts needed to be considered and managed, such as cumulative construction noise. In some instances, contractors shared the same construction sites and, for example, waste facilities. Importantly, as all these works were being delivered under the Crossrail Act 2008, all of them had to undertake their scope in accordance with the EMR.

In the case of utility companies and Network Rail, which normally work under permitted development rights and follow standard environmental management practices, the EMR requirement created practical challenges. This was particularly so when works were being undertaken by these organisations using their framework contractors that were procured under preexisting terms and conditions and agreed performance levels that did not always match those required by the EMR. For example, they required that a section 61 consent had to be obtained prior to construction works beginning, but this was not a standard requirement of the framework contactors, which in some instances required an instruction and consequent compensation.

\section{Role of the client}

Construction works began in 2009 and will run to 2018, encompassing nearly 100 construction sites of varying size and longevity. The numerous contractors and partners involved in the delivery meant that a strong client role was fundamental to delivering a high level of environmental performance and successfully addressing the environmental challenges posed by the scheme.

The size and scale of the project presented an opportunity to increase environmental performance beyond that which had been achieved on previous major infrastructure projects, and thereby set a new standard for future projects to measure themselves against. To that end the client established an aspirational environmental vision, 'Setting the standard for environmental performance and leaving the legacy of a sustainable railway', with the aim of ensuring that this opportunity would be grasped during the setting of objectives and targets and delivered through corresponding environmental management processes and procedures.

The following sections set out the way in which environmental standards were established for the programme and in particular the way in which all the various parties delivering the works were aligned to achieve these standards.

The client team also took the lead in liaising with key environmental stakeholders (principally the Environment Agency), using a single point of contact in the client team to ensure consistency of approach to issues and to assist the stakeholders in prioritising workload to assist with meeting programme requirements.

\section{Setting the standard}

One of the first tasks was to set the environmental standard for the project as aspired to by the vision. The EMR formed the basis for this, but had been expressed predominantly in terms such as to 'use reasonable endeavours', 'endeavour to ensure' and 'so far as reasonably practicable', which had the potential from a contractmanagement perspective to leave matters of performance open to interpretation.

To address the issue the client held a workshop in late 2009 consisting of some of the key infrastructure projects of the time. It was attended by representatives from the Olympic Delivery Authority, the Network Rail West Coast main line upgrade project, the East London line extension project and by the client's project delivery partner, Bechtel, as a deliverer of major infrastructure worldwide and in particular High Speed 1.

The purpose of the workshop was to identify what good performance looked like and thereby seek to set suitable objectives, targets and general requirements. The workshop concluded that, with the exception of waste, there was a distinct lack of environmental benchmark data for major infrastructure projects.

As a result a threefold approach was adopted.

- Where there was good authoritative independent information available, such as waste, the client would use it to set its requirements.

- Where good authoritative independent information was not available, but there was sufficient confidence in the level of expertise available within the project (including that of the contractors), the client would set nominal targets with a view to achieving and where practical exceeding them.

- Where there was insufficient information to set specific targets, performance would be monitored over time with a view to increasing performance and thereby leaving a suitable body of information for the setting of benchmarks in the future.

Some examples of each are presented in the following subsections. 


\subsection{Waste and materials resource management}

Data provided by the government's waste programme Wrap was used to set targets and stretch targets for waste, excavated material and recycled content that were considered to be at the top of existing good practice (see Table 1).

A client-led approach was adopted to the reuse of excavated material. Some of the destination sites and means of transportation were specified to contractors together with an allowance for flexibility, permitting some contractors to make their own arrangements for beneficial reuse where it was necessary for them to do so.

The benefit of adopting a client-led approach was that it allowed a significant proportion of the material (just over $3 \mathrm{Mt}$ ) to be used to create a landmark new nature conservation area as part of the Royal Society for the Protection of Birds' Wallasea Island project. The early definition of a solution reduced the programme risk associated with a potential lack of suitable disposal sites during the main tunnelling and excavation works.

It also allowed the development of infrastructure for the transportation by water and the early allocation of rail paths, which together contributed to $80 \%$ (per $\mathrm{t} \mathrm{km}$ ) of excavated material being transported by rail or water. This is explained in more detail in a paper available on the Crossrail Learning Legacy website (Mellings and Limna, 2017).

A bespoke Building Research Establishment (BRE) Smartwaste system was developed for waste and excavated material so that the principal contractors could input their information where the client had the ability to view and interrogate it. All contractors were required to update the system with their data every 4 weeks. The centralised reporting system allowed data reporting across the whole programme on the amount of waste diverted from landfill. This enabled the client to meet its obligations to implement the waste hierarchy and ensured that data reported was consistent between all contracts.

Contractors had to enter detailed information on each waste movement, thereby providing the client clear visibility of all waste movements and end uses, which was important for assurance purposes. As the project moved from heavy civil construction to the fit-out phase, it enabled a more focused study of construction waste.

Current performance levels against the targets are as follows.

- A total of just over $8 \mathrm{Mt}$ of material was excavated during construction. A total of $98 \%$ of the material was beneficially reused including $3 \mathrm{Mt}$ used to create a nature reserve at Wallasea Island. Although the stretch target was to reuse 100\% of material beneficially, this was not possible as not all of the material generated was suitable for reuse.

- A total of $98 \%$ of construction and demolition waste was diverted from landfill, exceeding the stretch target of $95 \%$.

- A total of $32 \%$ recycled content by value was achieved, exceeding the stretch target of $20 \%$.

\subsection{Environmental rating systems}

A review of available third-party independently verified environmental rating systems was commissioned to identify which, if any, could be applied to the project. The review recommended that Breeam should be used for stations, depots and certain other buildings and Ceequal for the remaining infrastructure, tunnels, portals and
Table 1. Waste targets

\begin{tabular}{|ll|}
\hline Material & Target \\
\hline $\begin{array}{l}\text { Clean excavated } \\
\text { material }\end{array}$ & $\begin{array}{l}\text { Reuse and recycle at least 95\% of clean } \\
\text { excavated waste, and aim to achieve 100\% }\end{array}$ \\
\hline Demolition waste & $\begin{array}{l}\text { Reuse and recycle at least } 90 \% \text { of demolition } \\
\text { waste, and aim to exceed } 95 \%\end{array}$ \\
\hline Construction waste & $\begin{array}{l}\text { Reuse and recycle at least } 90 \% \text { of } \\
\text { construction waste, and aim to exceed 95\% }\end{array}$ \\
\hline Recycled content & $\begin{array}{l}\text { At least 15\% of total material value derives } \\
\text { from reused and recycled content in new } \\
\text { construction, and aim to exceed } 20 \% \text { by } \\
\text { selecting the top opportunities to exceed this } \\
\text { figure without increasing the cost of materials }\end{array}$ \\
\hline
\end{tabular}

shafts. Through the use of these rating systems, environmental performance standards were set for design and construction.

Breeam was adopted for underground stations for the first time, utilising a bespoke methodology (Breeam Bespoke for Crossrail Underground Stations) especially developed by the BRE with criteria specifically tailored for application to Elizabeth line underground stations. The standard Breeam bespoke method was used on two surface stations, Custom House and Abbey Wood. The Breeam industrial method was applied to the depot and stabling siding facilities.

The application of Breeam to underground stations required the development and use of several underground-specific criteria for the assessment of the stations. In the absence of any previous benchmarks and following the advice of the BRE, the client asked all the designers' Breeam assessors for underground stations to recommend the most suitable rating level for each station. A minimum target rating of 'very good' was identified at the design stage and was included in the construction contracts. A stretch target of 'excellent' was also included, which would be decided by the principal contractors once they had been procured. Both Custom House and Abbey Wood stations were set a target of 'very good', and currently all contracts using Breeam are set to achieve 'very good'.

Ceequal was used for tunnels, portals and shafts - 12 contracts in all. Interim certificates were obtained for the designs prior to procurement of the principal contractors and, in all cases, achieved a rating of 'excellent'. This was then carried forward into the construction phase with all contractors required to maintain the 'excellent' rating. At the time of reporting, ten contracts have achieved 'excellent' and the remaining two are on course to do so.

\subsection{Construction energy}

The setting of construction energy reduction targets initially proved challenging due to the absence of reliable and relevant benchmark data. Consultation with Constructing Excellence identified that industry benchmarks were biased to smallerscale projects and not representative of heavy civil engineering. The principal contractors were also lacking reliable data.

A collaborative approach was therefore taken, with the development of a carbon dioxide and energy management plan, and contractors identifying opportunities for reduction within the scope of their works. The contractors identified a range of potential carbon dioxide reduction performances against their baselines, ranging between $4 \%$ and $8 \%$. 
A target reduction figure of $8 \%$ was eventually agreed and applied to all the construction contracts. In addition, this target was then set as one of the client's corporate key performance indicators, which had senior management bonuses tied to performance against them. At the time of reporting, a 15\% reduction against the baseline is being achieved.

\subsection{Construction noise}

Noise has been one of the main impacts and challenges during the construction of the Elizabeth line. It was recognised that for the principal contractors to achieve the necessary levels of performance in noise management, the focus could not solely be on controlling or minimising noise levels and that setting targets for these or for the number of complaints would not be effective measures.

Instead, factors such as community engagement, effective planning, management processes, leadership and culture were identified as being critical to successful noise management on sites. A corresponding suite of performance criteria was developed for construction noise and vibration management. The aim was to drive improved performance and the criteria were incorporated into the supplier-performance process (see Section 7).

Performance against the criteria was monitored and tracked. With each successive round of assessment and scoring, the contractors steadily improved in noise management performance as illustrated in Figure 3.

\section{Providing assurance}

A key requirement for the client was to be able to demonstrate that the EMR and any of the project's other environmental requirements were met during design and construction. This was achieved by developing and implementing an environmental management system certified to ISO 14001 (ISO, 2015) and integrating it within the overall project management system.

One of the first tasks was the procurement of designers and contractors with the appropriate skills and competencies to implement the environmental requirements, which were therefore written into the contracts. All principal contractors were required to have experienced environmental personnel (e.g. environment

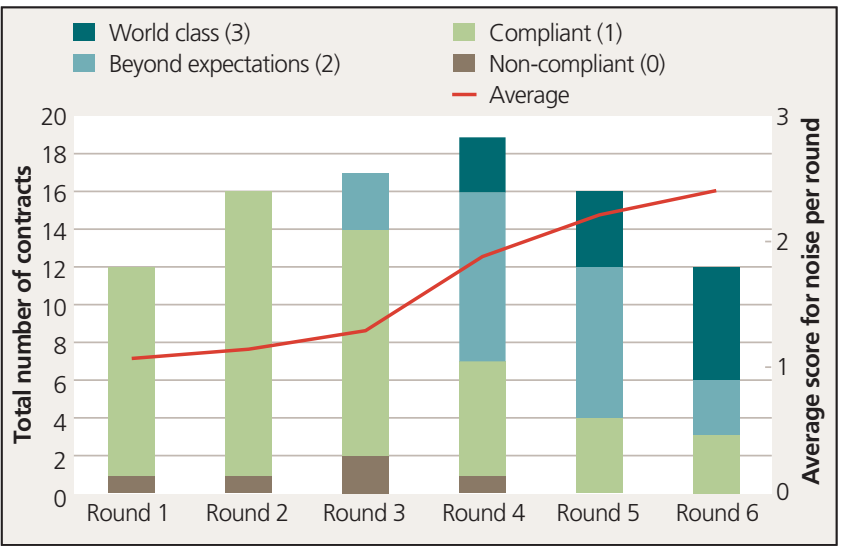

Figure 3. Contractor improvement in noise management through performance assurance managers and waste managers) and have a certified environmental management system.

A regime of audits and inspections was used to check compliance. The client employed environmental advisors whose role it was to work on a day-to-day basis with the principal contractors, providing assurance that they were meeting the environmental requirements. The close client-contractor working relationships that developed also provided a source of expert advice and assistance to the contractors, and aided coordination of cumulative impacts where several contractors were working in one location.

Notwithstanding the overall effectiveness of the environmental management system, there was initially a lack of visibility in the early stages of each contractor's overall environmental performance as it related to the relevant environmental requirements - particularly those not covered by regularly reported key performance indicators. This was true of a number of other performance areas such as in community relations, commercial management and social sustainability.

In response, the client developed a supplier-performance process to provide an objective measure of each contractor's performance. It complemented the project management systems processes by providing a structured framework which enabled objective assessment of principal contractors. It provided visibility of performance of each contractor and enabled benchmarking of their performance relative to one another.

The client worked collaboratively with its principal contractors to develop a detailed suite of objective environmental performance measures. These measures were each allocated a score ranging from 'zero' (non-compliant performance, that is not meeting the obligations under the works information) through to 'one' (compliant performance, that is meeting the obligations under the contract), following on to 'two' (performance beyond the requirements to value-added performance) and finally 'three' (world-class performance, either working beyond or significantly working beyond the obligations of the contract).

Measures were defined as inputs or outputs. Typically, an input might be a plan of action, for example an energy management plan; an output would be the corresponding energy savings from implementation of the plan. This enabled the performance of each contract to be plotted visually on a graph, such as the one illustrating environmental performance at a point in time as shown in Figure 4.

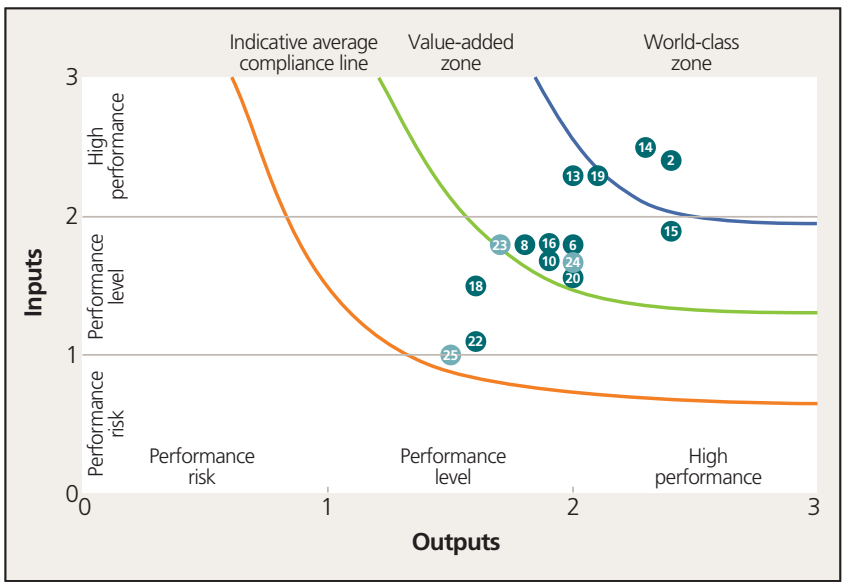

Figure 4. Performance assurance contractor scores - final round 
This is explained in more detail in a paper on the Crossrail Learning Legacy website (Locke and Myatt, 2016).

Typically, when the supplier-performance process was first established, performance was generally towards the lower left side of the graph. Performance quickly moved into the value-added and even towards the world-class zones as contractors wanted not only to demonstrate their own good performance but to compete effectively against the performance of their peers.

\section{Governance and leadership}

Visible leadership commitment to achieve the environmental targets was essential to their successful delivery. At the highest level, the client established the sustainability subcommittee which reported directly to the executive committee. This was chaired by the chief executive officer, with other members including the programme director, delivery director, finance director, talent and resources director and several non-executive directors (Figure 5).

The visibility of environmental performance was important to the successful functioning of the committee and was provided through the use of key performance indicators presented on an

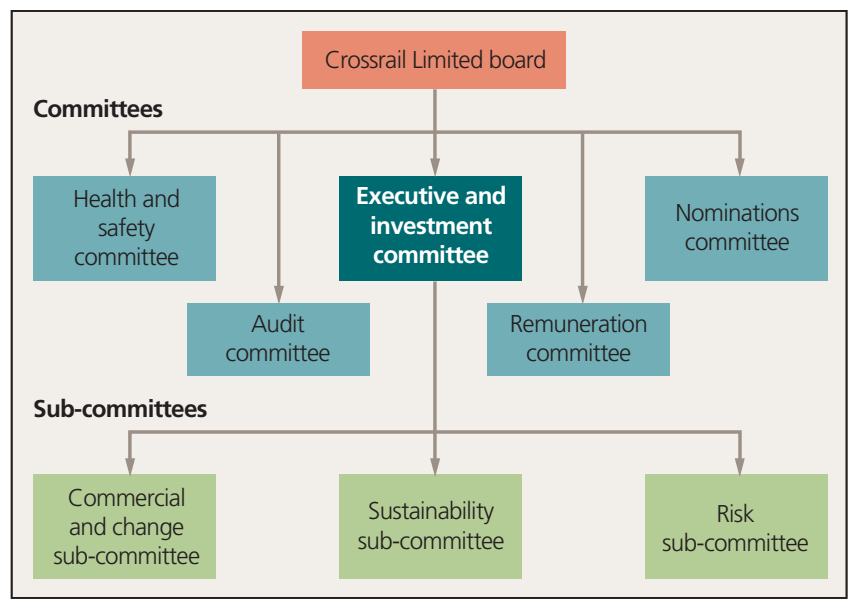

Figure 5. Crossrail Limited executive committee structure

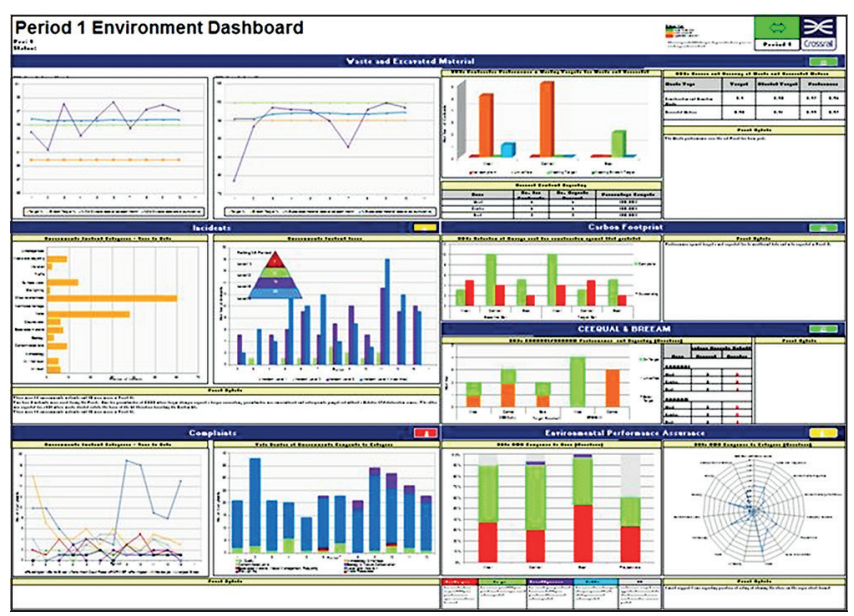

Figure 6. Example environment dashboard environmental dashboard (Figure 6). The dashboard provided information on how well the project was performing overall as well as how individual contracts were performing against project targets and measures. As a consequence, the committee was able to monitor any areas requiring improvement and direct any actions to do so.

\section{Engagement and recognition}

Recognition and highlighting the positive were important to encourage performance beyond the norm. To that end the client established a scheme for rewarding positive environmental behaviour known as the Green Line recognition scheme (Figure 7). The scheme set and rewarded key factors involved in promoting positive environmental behaviour on sites and focused on the 'how' of environmental performance in addition to the 'what'. This is explained in more detail in a paper on the Crossrail Learning Legacy website (Mellings and Myatt, 2016).

The client held annual sustainability awards that reflected performance across the three areas of social, economic and environmental sustainability. Specific environmental categories were focused on environmental engagement, performance and innovation, and the awards extended to reward both team and individual performance.

Various mechanisms were used to encourage contractors and partners to share knowledge. These included workshops for specific issues (such as materials resource management workshops and Breeam/Ceequal client-facilitated workshops) and regular forums such as an environment managers' forum, an energy management working group, ethical supply chains in the construction working group and carbon dioxide working group.

Information was shared by way of a collaboration website and libraries of best practice, including the Green Line library for behavioural work and the Innovate18 database (now transferred to the infrastructure industry innovation portal, I3P) (Knowledge Transfer Network, 2017) for best practice.

In addition to formal mechanisms, the environment managers working for different contracts worked together informally to share experience and lessons learned. For example, the use of community wood recycling was a shared practice, which was picked up by a number of contracts.

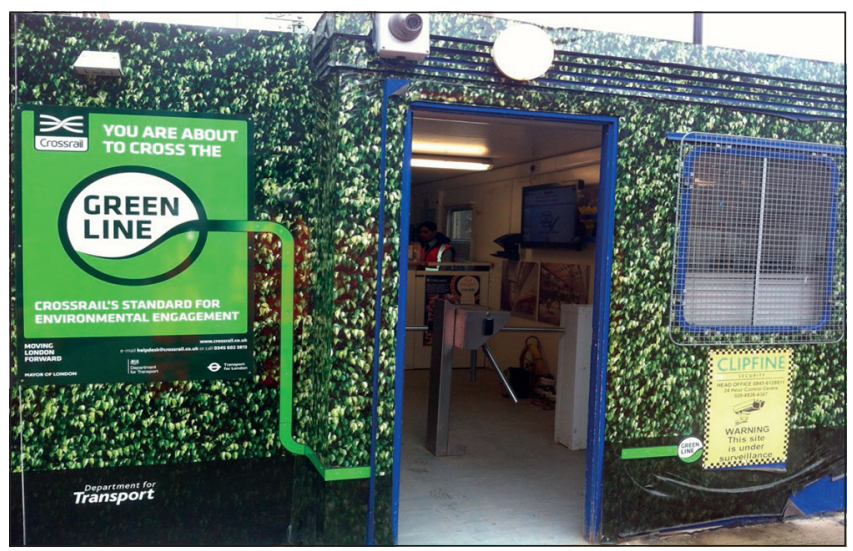

Figure 7. Green Line treatment at site entrance 
Civil Engineering

Volume 170 Issue CE6
Crossrail project: environmental management

during delivery of London's Elizabeth line

Paris, Myatt and de Silva

\section{Innovation}

Crossrail Limited established an innovation programme, which among other things promoted the adoption of techniques and practices to raise the level of industry performance. One such example was the use of drill-and-burst technology taken from the minerals sector and used to break down a diaphragm wall next to Paddington station, thereby reducing the risk of adverse vibration impact on the grade 1 listed building structure and inhabitants (Figure 8). This is explained further in a paper on the Crossrail Learning Legacy website (Bird et al., 2016).

Also significant was the combined contribution of all principal contractors, which provided a momentum to effect some of the changes. An example of this was a requirement to implement diesel emissions controls on construction (non-road mobile) machinery. A total of $84 \%$ of non-road mobile machinery on the project was fitted with particulate filters or used cleaner $3 \mathrm{~B}$ engines. Implementation across all contracts provided a stock of compliant machinery that could be employed on subsequent projects. It was also used as evidence to assist the Greater London Authority in publishing supplementary planning guidance to establish this as a requirement across London.

\section{Conclusion}

The approach taken on the Crossrail project has been to set clear and stretching best practice targets, where these could be confidently identified based on existing industry performance levels. These were possible, for example, in construction, demolition and excavation waste, recycled content and environmental rating schemes.

In some instances, the combined expertise of the client, Crossrail Limited, and its principal contactors was used to set performance targets, such as for construction energy reduction. Where specific targets could not be robustly determined, performance measures were identified and tracked, such as those for construction noise and vibration.

Performance against the targets was then monitored within an integrated performance management and reporting system that enabled accurate, insightful and rapid assessment of performance

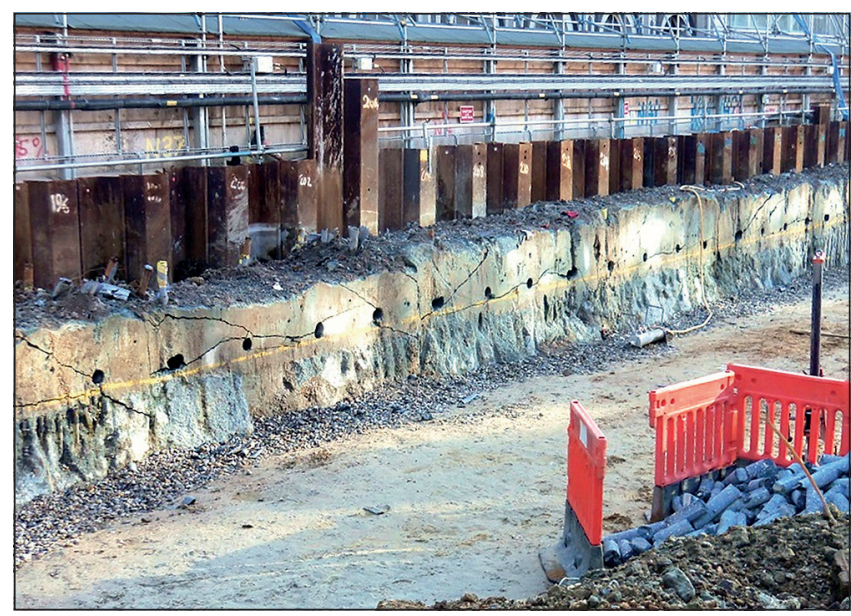

Figure 8. 'Drill-and-burst' technique for removing diaphragm wall and progress. This was visible at all levels of the organisation, from the board all the way down to individual contract project managers. The supplier-performance process was key in this regard, providing an understanding of performance of each principal contractor and comparison with their peers.

Working beyond the project's best practice requirements was further encouraged through mechanisms such as the Green Line recognition scheme, annual awards and collaboration and sharing of best practice using forums, workshops and website-sharing tools. Innovation was important, with a particular focus on innovation in key areas where a difference could be made.

As a result of various measures, the project's environmental performance has so far met, or exceeded, the targets that were set for construction - and remains on course to do so at completion. The client has sought to demonstrate by example that a major project can meet the environmental commitments made during the authorisation process and on completion.

The aim is to leave a tangible legacy that sets the benchmark for environmental performance against which future major infrastructure projects can be measured.

\section{References}

Bird A, Cobbing C, Keeley D et al. (2016) Vibration Management and Listed Buildings. Crossrail Learning Legacy, Crossrail, London, UK. See http:// learninglegacy.crossrail.co.uk/documents/vibration-management-andlisted-buildings/ (accessed 15/08/2017).

Bennett S (2017) Crossrail project to deliver London's Elizabeth line: the parliamentary bill process. Proceedings of the Institution of Civil Engineers Civil Engineering 170(6): 10-14, http://dx.doi.org/10.1680/jcien.17.00014.

Carver J (2014) Crossrail - Portals to the Past - an Exhibition of Archaeology Finds 2014. Museums and Heritage Advisor, Worcester, UK. See http:// advisor.museumsandheritage.com/features/crossrail-portals-to-the-pastan-exhibition-of-archaeology-finds-2014/ (accessed 04/07/2017).

Crossrail (2017) http://www.crossrail.co.uk/sustainability/environmentalsustainability/environmental-policy-and-objectives (accessed 15/08/2017).

Crossrail Act 2008. Chapter 18. Her Majesty's Stationery Office, London, UK

Crossrail Learning Legacy (2016) Archaeology. See http://learninglegacy. crossrail.co.uk/learning-legacy-themes/environment/archaeology/ (accessed 04/07/17)

ISO (2015) ISO 14001:2015: Environmental management systems Requirements with guidance for use. ISO, Geneva, Switzerland.

Knowledge Transfer Network (2017) I3P. See https://www.i3p.org.uk/ (accessed 02/06/2017)

Lloyd-Davies K and Rowark M (2017) Crossrail project: procuring infrastructure for London's Elizabeth line. Proceedings of the Institution of Civil Engineers - Civil Engineering 170(6): 35-41, http://dx.doi. org/10.1680/jcien.17.00002.

Locke R and Myatt C (2016) Environmental Performance Assurance of Civil and Station Construction Works. Crossrail Learning Legacy, Crossrail, London, UK. See http://learninglegacy.crossrail.co.uk/documents/ environmental-performance-assurance-civil-station-construction-works/ http://learninglegacy.crossrail.co.uk/documents/lessons-learned-greenline-scheme/ (accessed 02/06/2017).

Mellings L and Limna G (2017) Excavated Materials Story. Crossrail Learning Legacy, Crossrail, London, UK. See http://learninglegacy.crossrail.co.uk/ documents/excavated-materials-story/ (accessed 02/06/2017).

Mellings L and Myatt C (2016) Promoting Positive Environmental Behaviour Change at Crossrail - Lessons Learned from Implementing the Green Line Recognition Scheme. Crossrail Learning Legacy, Crossrail, London, UK. See http://learninglegacy.crossrail.co.uk/documents/lessons-learnedgreen-line-scheme/ (accessed 02/06/2017). 